\title{
PENGARUH EXPERIENTIAL MARKETING TERHADAPLOYALITAS PENGGUNA SMARTPHONE SAMSUNG
}

\author{
Ahmad Soleh ${ }^{1}$ \\ Dosen Tetap Muhammadiyah Jambi ${ }^{1}$ \\ ahmad.soleh@umjambi.ac.id \\ Agesha Marsyaf ${ }^{2}$ \\ Dosen Tetap Muhammadiyah Jambi ${ }^{2}$ \\ agesha.marsyaf.am@gmail.com \\ Frillisia Saputri ${ }^{3}$ \\ Mahasiswa Universitas Muhammadiyah Jambi ${ }^{3}$ \\ Frillisiasaputri12@gmail.com
}

\begin{abstract}
Ringkasan
Penelitian ini berjudul tentang "Pengaruh experiential marketing terhadap loyalitas pengguna smartphone samsung”. Adapun yang menjadi tujuan dari penelitian ini adalah sebagai berikut: (1)Untuk mengetahui dan menganalisis pengaruh experiential marketing terhadap loyalitas pengguna smartphone samsung. (2)Untuk mengetahui variabel mana dari experiential marketing yang paling berpengaruh terhadap loyalitas pengguna smartphone samsung. Berdasarkan hasil penelitian dan pembahasan dapat ditarik kesimpulan sebagai berikut: (1)Hasil pengujian hipotesis secara serempak menunnjukkan bahwa variabel experiential marketing yang terdiri dari : sense, feel, think, act, dan relate berpengaruh positif dan signifikan terhadap loyalitas pengguna smartphone samsung. (2) Hasil pengujiaan hipotesis secara parsial menunjukkan bahwa variabel sense, think, act, dan relate berpengaruh terhadap loyalitas pengguna smartphone samsung sedangkan variabel feel tidak memiliki pengaruh terhadap loyalitas pengguna smartphone samsung.
\end{abstract}

Kata Kunci : Experiential Marketing, Loyalitas, Smartphone samsung.

\section{PENDAHULUAN}

Perkembangan teknologi komunikasi dari tahun ke tahun semakin lama semakin canggih. Hal ini dikarenakan pola konsumsi konsumen pada saat ini yang selalu menginginkan sebuah kemudahan dalam komunikasi yang dapat mendukung kegiatan mereka sehari-hari baik dalam pekerjaan maupun hal yang lainnya. Karna nya banyak produsen alat komunikasi yang menawarkan berbagai jenis produk baru dengan inovasi yang berbeda dari produk - produk sebelumnya, dimana produk yang dihasilkan banyak memberikan kemudahan bagi para konsumen dalam melakukan komunikasi.

Dunia bisnis produk komunikasi berlomba - lomba supaya dapat menarik minat para masyarakat dan memutuskan membeli serta menggunakan produknya. Berbagai perusahaan handphone meluncurkan smartphone seperti Apple, Samsung, Sony Ericson, Nokia, Xiaomi, LG Elecronik, dan sebagainya. Samsung merupakan salah satu perusahaan handphone yang memproduksi smartphone berbasis android. Android adalah sebuah operating system (os) yang 
dikembangkan oleh Google untuk mobile device atau yang lebih kita kenal sebagai smartphone. Salah satu kelebihan dari android adalah ketersediaan aplikasi dari berbagai macam kategori: social, hiburan, permainan, dan lain-lain.

Worldwide Smartphone Sales to End Users by Vendor in $4 Q 19$ (Thousands of Units)

\begin{tabular}{|c|c|c|c|c|}
\hline Company & 2019 units & $\begin{array}{c}2019 \text { Market Share } \\
(\%)\end{array}$ & 2018 Units & $\begin{array}{c}\text { 2018 Market } \\
\text { Share (\%) }\end{array}$ \\
\hline Samsung & $75,111.8$ & 20.4 & $72,336.4$ & 19.3 \\
\hline Huawei & $58,055.7$ & 15.8 & $49,486.5$ & 13.3 \\
\hline Apple & $38,522.9$ & 10.5 & $44,715.1$ & 11.9 \\
\hline Xiaomi & $33,191.5$ & 9.0 & $32,825.5$ & 8.8 \\
\hline Oppo & $28,112.2$ & 7.6 & $28,511.1$ & 7.6 \\
\hline Others & $134,913.3$ & 36.7 & $146,096.1$ & 39.0 \\
\hline Total & $367,908.1$ & 100.0 & $374,330.6$ & 100.0 \\
\hline
\end{tabular}

Source: Gartner (August 2019)

Di peringkat pertama dalam daftar Gartner adalah perusahaan korea selatan, Samsung. Gartner mencatat bahwa samsung tetap merajai pabrikan smartphone global dengan pangsa pasar 20,4 persen dan mengapalkan 75 juta unit smartphone dalam selama periode ini. Samsung mengalami kenaikan dari periode sebelumnya yang mencapai 19,3 persen. Galaxi A series disebut menjadi penyumbang terbesar peningkatan ini.

TOP BRAND AWARD Top Brand For Teens Index 2019 (KATEGORI IT)

\begin{tabular}{|c|c|c|}
\hline \multicolumn{3}{|c|}{ SMARTPHONE } \\
\hline MEREK & TBI & TOP \\
\hline Samsung & $45,8 \%$ & TOP \\
\hline Oppo & $16,6 \%$ & TOP \\
\hline Xiaomi & $14,3 \%$ & TOP \\
\hline Vivo & $4,5 \%$ & - \\
\hline Lenovo & $3,7 \%$ & - \\
\hline
\end{tabular}

Source: www.topbrand-award.com tahun 2019

Menurut survey TBA kategori IT/ smartphone pada tahun 2019 smartphone merek samsung menjadi peringkat pertama dengan index 45,8\%, kemudian disusul competitornya oppo dengan index $16,6 \%$, xiaomi dengan index $13,3 \%$ serta vivo dengan index $4,55 \%$, dan 
Lenovo dengan index 3,7\%. Hasil ini membuktikan bahwa samsung menjadi brand top yang diminati dan digemari masyarakat.

Setelah membeli dan dan menggunakan suatu produk, seorang konsumen akan mengalami kepuasaan dan ketidakpuasan. Ketika pelanggan merasa puas secara konsisten dan berkelanjutan, maka mereka ingin terus mengulangi pengalaman konsumsi yang memberikan kepuasan ini dengan melakukan pembelian ulang serta merekomendasikannya pada orang lain disekitar. Fenomena yang terjadi yaitu semakin banyaknya merek yang muncul menjadikan persaingan semakin ketat dan mengenali kebutuhan untuk mengkombinasikan teknologi digital dan pengalaman personal untuk terhubung dengan konsumen secara efektif, tidak hanya sebagai pelengkap gaya hidup, tetapi juga sebagai kebutuhan dalam membantu kegiatan kantor dan bisnis serta aktivitas lainnya. Semakin banyaknya merek smartphone yang muncul pada masa ini membuat terjadinya persaingan diantara sesama produsen untuk merebut perhatian konsumen dan mempertahankan loyalitas konsumen dengan merasakan pengalaman emosi fisik dan membantu hubungan dunia online dan ofline.

Untuk menumbuhkan loyalitas bagi pengguna smatphone samsung sebagai keputusan pembelian akhir, maka produsen melalui produknya perlu menghadirkan pengalaman yang unik, positif dan mengesankan kepada konsumen. Experiential marketing bertujuan untuk meningkatkan loyalitas jangka panjang dan juga mengikat konsumen

Experiential marketing bukan sekedar memainkan peran yang sangat penting dalam pengambilan keputusan, tetapi sekaligus merupakan perekat kuat untuk menciptakan loyalitas. Sehingga menunjukan bahwa experiential marketing dapat menghadirkan kepuasan konsumen yang pada akhirnya menghasikan customer loyalt.

\section{TINJAUAN TEORITIS}

\section{Manajemen Pemasaran}

Menurut Kotler (2014) menyatakan bahwa: "pemasaran adalah proses dimana perusahaan menciptakan nilai bagi pelanggan dan membangun hubungan yang kuat dengan pelanggan bertujuan untuk menangkap kepuasan dari pelanggan sebagai imbalannya.” Kata manajemen didefinisikan sebagai sebuah proses rangkaian kegiatan perencanan, pengorganisasian, penggerakan dan controlling (pengawasan) yang dilakukan untuk mencapai target atau tujuan yang telah ditentukan sebelumnya, dan difinisi pemasaran yaitu suatu kegiatan didalam perekonomian yang dapat membantu menciptakan nilai ekonomi, nilai tersebut adalah produksi, pemasaran, dan konsumsi. 
Menurut Buchari Alma (2015), manajemen pemasaran adalah proses untuk meningkatkan efisiensi dan efektivitas dari kegiatan pemasaran yang dilakukan oleh individu atau oleh perusahaan. Menurut Philip Kotle/Amstrong (2016 ), manajemen pemasaran adalah analisis, perencanaan, pelaksanaan, dan pengandalian atas program yang dirancang untuk menciptakan, membangun, dan mempertahankan pertukaran yang menggabungkan dengan pembeli sasaran dengan maksud untuk mencapai asaran organisasi.

\section{Pengertian Produk}

Produk didefinisikan oleh Kotler dalam buku H.Abdul Manaf (2016) mengemukakan produk yaitu $A$ product is anything that can be offered to a market to satisfy a want or need. Product that are marketed include physical good, services, events, persons, places, properties, organization, information and ideas, yang artiya produk adalah segala sesuatu yang dapat ditawarkan di pasar, untuk memuaskan kebutuhan dan keinginan konsumen. Produk terdiri atas barang, jasa, pengalaman, events, orang, tempat, kepemilikan, organisasi, informasi dan ide. Kualitas produk merupakan pemahaman bahwa produk yang ditawarkan oleh penjual mempunyai nilai jual lebih yang tidak dimiliki oleh produk pesaing, oleh karna itu perusahaan berusaha memfokuskan pada kualitas produk dan membandingkannya dengan produk yang ditawarkan oleh perusahaan lain.

\section{Experiential Marketing}

Menurut Schmitt (2005) Experiential marketing merupakan promosi yang dapat dilakukan perusahaan sehingga merangsang pelanggan untuk membeli dan melakukan pembelian ulang. Experiential marketing adaah sebuah pendekatan untuk memberikan informasi yang lebih dari sekedar informasi mengenai sebuah produk.

Menurut Schmitt (1999) bahwa pengalaman adalah peristiwa khusus yang terjadi pada orang sebagai tanggapan atas beberapa jenis rangsangan. Pengalaman merupakan hasil pengamatan atau keterlibatan dalam peristiwa nyata atau rekayasa. Menurut Kartajaya (2007) Experiental marketing adalah suatu konsep pemasaran yang bertujuan untuk membentuk konsumen-konsumen yang loyal dengan menyentuh emosi mereka dan memberikan suatu feeling yang positif terhadap produk.

\section{Komponen Experiential Marketing}

Menurut Bernd H Schmitt (1999 : 64) komponen Experiential marketing terbagi menjadi lima (5) bagian, yaitu:

\section{Panca indera (Sense)}


Sense marketing mempunyai daya Tarik dengan indera, bertujuan untuk menciptakan pengalaman sensorik melalui penglihatan, suara, sentuhan, rasa, dan penciuman. Menurut Bernd H. Schmitt (1999) Tujuan keseluruhan sense ini adalah untuk menciptakan kesenangan estetika, kegembiraan, keindahan, dan kepuasan melalui rangsangan indera.

\section{Perasaan ( Fell)}

Feel marketing menarik perasaan dan emosi pelanggan, dengan tujuan menciptakan pengalaman afektif dari suasana hati positif terkait dengan merek, sampai emosi yang kuat dari kegembiraan dan kebanggaan. Yang diperlukan dalam feel marketing adalah pemahaman dari stimulus apa yang dapat memicu emosi tertentu serta kemauan pelanggan untuk terlibat dalam pengambilan perspektif dan empati. (Bernd H Schmitt, 1999). Untuk mencapai feel marketing yang dibutuhkan adalah pendekatan yang bisa membangkitkan emosi pelanggan dengan mengusahakan pelanggan agar merasa feel good.

\section{Cara Berpikir ( Think )}

Think marketing menarik untuk kecerdasan dengan tujuan penciptaan kognitif, pengalaman pemecahan masalah yang melibatkan pelanggan secara kreatif. Think menarik untuk melibatkan pelanggan berfikir memusat dan menyebar melalui kejutan (suprise), intrik (inrigue), dan provokasi (provocation). (Bernd H Schmitt, 1999)

Tujuan dari think marketing adalah membawa pelanggan mampu berfikir lebih mendalam dan kreatif sehingga memberikan opini yang bagus terhadap produk dan service perusahaan.

\section{Perilaku ( Act)}

Act marketing bertujuan untuk mempengaruhi pengalaman tubuh, gaya hidup, dan interaksi. Dimana gaya hidup sendiri merupakan pola perilaku individu dalam hidup yang di refleksikan dalam tindakan, minat, dan pendapat. Act marketing memperkaya kehidupan pelanggan dengan meningkatkan pengalaman fisik mereka dan menunjukkan kepada pelanggan. Biasanya perubahan gaya hidup lebih memotivasi, menginspirasi, dan spontan secara alami serta dibawa oleh panutan, (role model, bintang film atau atliet terkenal). Iklan pada Act marketing menunjukkan hasil perilaku atau gaya hidup. (Bernd H Schmitt, 1999).

\section{Pertalian ( Relate )}

Menurut Bernd H. Schmitt (1999) Relate marketing adalah berisi aspek dari pemasaran sense, feel, think dan act. Namun relate marketing berkembang melampaui kepribadian individu, perasaan pribadi, demikian menambah " pengalaman individu" dan mengaitkan 
individu tersebut dengan dirinya sendiri, orang lain, atau budaya yang di reflesikan dalam brand.

\section{Loyalitas Pelanggan}

Menurut Kotler dan Keller (2009) loyalitas adalah komitmen yang dipegang secara mendalam untuk membeli atau mendukung kembali produk atau jasa yang disukai di masa depan meski pengaruh situasi dan usaha pemasaran berpotensi menyebabkan pelanggan beralih. Menurut Griffin (2003) loyalitas adalah seorang konsumen yang dikatakan setia atau loyal apabila konsumen menunjukkan perilaku pembelian secara teratur atau terdapat suatu kondisi dimana mewajibkan membeli paling sedikit dua kali dalam selang waktu tertentu.

Menurut pendapat Kotler \& Keller (2012) indikator loyalitas pelanggan adalah:

1. Kesetiaan terhadap pembelian produk.

2. Ketahanan terhadap pengaruh yang negatif mengenai perusahaan.

3. Mereferensikan secara total esitensi perusahaan.

Loyalitas dapat didefinisikan sebagai suatu kecenderungan emosi terhadap suatu objek, dimana emosi ini didapat dari pengalaman terdahulu atau berasal dari informasi-informasi yang didapat dari orang lain. Dapat disimpulkan loyalitas adalah suatu ikatan perasaan atau ketergantungan seseorang terhadap suatu objek yang mana di dalamnya terdapat keinginan untuk menjaga, memiliki, dan setia pada objek tersebut.

\section{METODE PENELITIAN}

Penelitian ini menggunakan pendekatan Explanatory (penjelasan) dengan metode kuantitatif Singarimbun dan Effendi (2008), dengan menggunakan data primer. Dalam penelitian ini menggunakan sampel sebanyak 150 sampel yang berasal dari dua perguruan tinggi (Universitas Jambi dan Universitas Muhammadiyah Jambi). Sampel atau responden yang dipilih adalah mahasiswa dengan tujuan untuk mendapatkan jawaban yang lebih akurat karena responden di anggap mampu dan lebih mengetahui tentang produk-produk smartphone terutama Samsung. Alat analisis data yang digunakan dalam penelitian ini adalah regresi linier berganda dengan model sebagai berikut:

$$
Y=\alpha+\beta_{1} X_{1}+\beta_{2} X_{2}+\beta_{3} X_{3}+\beta_{4} X_{4}+\beta_{5} X_{5}+e
$$




$\begin{array}{ll}\text { Dimana : } & \\ \mathrm{Y} & : \text { Loyalitas } \\ \alpha & : \text { Konstanta } \\ \beta_{1, \beta 2, \beta 3, \beta_{4}, \beta_{5}} & : \text { Koefesien Regresi } \\ \mathrm{X} 1 & : \text { Panca Indera } \\ \mathrm{X} 2 & : \text { Perasaan } \\ \mathrm{X} 3 & : \text { Cara Berpikir } \\ \mathrm{X} 4 & : \text { Perilaku } \\ \mathrm{X} 5 & : \text { Pertalian } \\ \mathrm{e} & : \text { Eror }\end{array}$

Selanjutnya analisis dilanjutkan dengan uji t, uji $\mathrm{F}$ dan koefisien determinasi

\section{HASIL PEMBAHASAN}

\section{Analisis Hasil Regresi}

Variabel bebas dalam penelitian terdiri dari sense $\left(\mathrm{X}_{1}\right)$, feel $\left(\mathrm{X}_{2}\right)$, think $\left(\mathrm{X}_{3}\right)$, act $\left(\mathrm{X}_{4}\right)$, relate $\left(\mathrm{X}_{5}\right)$ dan loyalitas $(\mathrm{Y})$.

\section{Pengujian secara parsial (Uji T)}

Berdasarkan hasil pengujian dalam menggunakan SPSS22 dengan metode regresi linear berganda maka diperoleh hasil sebagai berikut:

\section{Hasil Uji Koefisien Regresi Linear Berganda}

\begin{tabular}{|c|c|c|c|c|c|c|}
\hline \multicolumn{7}{|c|}{ Coefficients $^{\mathrm{a}}$} \\
\hline \multirow{2}{*}{\multicolumn{2}{|c|}{ Model }} & \multicolumn{2}{|c|}{ Unstandardized Coefficients } & \multirow{2}{*}{$\begin{array}{c}\begin{array}{c}\text { Standardized } \\
\text { Coefficients }\end{array} \\
\text { Beta }\end{array}$} & \multirow[b]{2}{*}{$\mathrm{T}$} & \multirow[b]{2}{*}{ Sig. } \\
\hline & & $\mathrm{B}$ & Std. Error & & & \\
\hline 1 & (Constant) & 10,936 & 1,015 & & 10,775 &, 000 \\
\hline & Sense &, 143 & 064 &, 183 & 2,229 &, 027 \\
\hline & Fell & 087 & ,097 & 074 & ,896 & ,372 \\
\hline & Think & ,209 &, 050 & ,334 & 4,028 &, 000 \\
\hline & Act & , 173 &, 044 & ,319 & 3,934 &, 001 \\
\hline & Relate & , 126 & 059 &, 008 & 2,175 &, 031 \\
\hline
\end{tabular}

a. Dependent Variable: Loyalitas Pelanggan

Dari hasil analisis regresi linier berganda dapat dihasilkan persamaan regresi sebagai berikut:

$\mathrm{Y}=10,936+0,143 \mathrm{X}_{1}+0,087 \mathrm{X}_{2}+0,209 \mathrm{X}_{3}+0,173 \mathrm{X}_{4}+0,006 \mathrm{X}_{5}+\mathrm{e}$

Dilihat dari data yang diperoleh nilai t-hitung dari setiap variabel bebas (independent) dalam penelitian ini. Nilai t-hitung dari setiap variabel bebas (independent) akan dibandingkan dengan nilai t-tabel dengan menggunakan tingkat kepercayaan (confidence interval) $95 \%$ atau $\alpha$ 
$=0,05$ dimana $\mathrm{df}=$ jumlah sampel - jumlah variabel $=150-6=144$ maka diperoleh nilai $\mathrm{t}$-tabel 1,976 .

Dari hasil Uji T akan diketahui pengaruh setiap variabel bebas (independent variabel) terhadap variabel terikatnya (dependent variabel) sebagai berikut ini

1. Nilai t-hitung untuk variabel sense sebesar 2,229 > nilai t-tabel sebesar 1,976 dan nilai signifikannya sebesar 0,027 < alpha 0,05. Artinya, Ho ditolak dan Ha diterima. Dapat disimpulkan bahwa variabel sense secara parsial berpengaruh positif dan signifikan terhadap loyalitas pengguna smartphone samsung.

2. Nilai t-hitung untuk variabel feel sebesar $0,897<$ nilai t-tabel sebesar 1,976 dan nilai signifikannya sebesar $0,372>$ alpha 0,05. Artinya Ho diterima dan Ha ditolak. Berdasarkan hasil yang diperoleh, berarti bahwa variabel feel secara parsial tidak berpengaruh positif dan signifikan terhadap loyalitas pengguna smartphone samsung.

3. Nilai t- hitung untuk variabel think sebesar 4,028 nilai t-tabel sebesar 1,976 dan nilai signifikannya sebesar $0,000<$ alpha 0,05. Artinya, Ha diterima dan Ho ditolak. Berdasarkan hasil yang diperoleh, berarti bahwa variabel think secara parsial berpengaruh positif dan signifikan terhadap loyalitas pengguna smartphone samsung.

4. Nilai t- hitung untuk variabel act sebesar 3,934> nilai t-tabel sebesar 1,976 dan nilai signifikannya sebesar 0,001 < alpha 0,05. Artinya Ho ditolak dan Ha diterima. Berdasarkan hasil yang diperoleh, berarti bahwa variabel act secara parsial berpengaruh positif dan signifikan terhadap loyalitas pengguna smartphone samsung.

5. Nilai t- hitung untuk variabel relate sebesar 2,175 > nilai t-tabel sebesar 1,976 dan nilai signifikannya sebesar 0,031 < alpha 0,05. Artinya Ho ditolak dan Ha diterima. Berdasarkan hasil yang diperoleh, berarti bahwa variabel relate secara parsial berpengaruh positif dan signifikan terhadap loyalitas pengguna smartphone samsung.

Berdasarkan hasil pengujian secara parsial terhadap masing-masing variabel, maka yang memberikan pengaruh yang dominan terhadap loyalitas pelanggan adalah variabel Think $\left(\mathrm{X}_{3}\right)$ karena memiliki koefisien regresi yang lebih besar yaitu 0,209. 


\section{Pengujian secara bersama-sama (Uji F)}

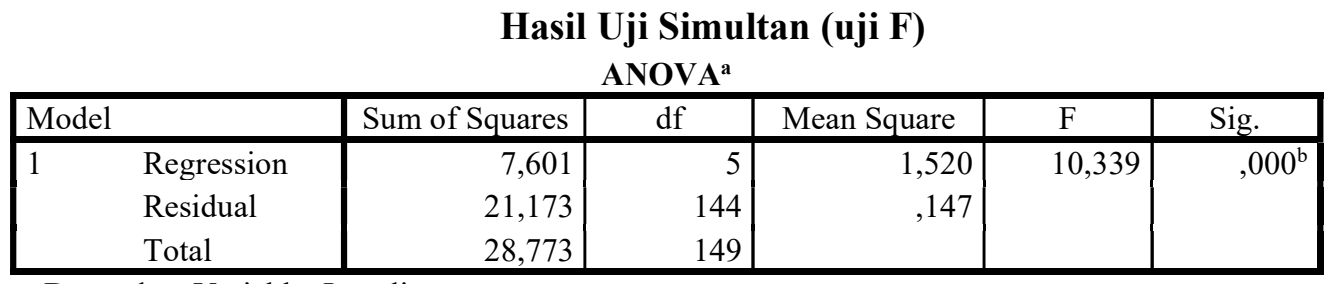

a. Dependent Variable: Loyalitas

b. Predictors: (Constant), Relate, Think, Fell, Think, Sense

Sumber: data diolah, 2020

Berdasarkan Tabel diperoleh nilai F-hitung sebesar 10,339 dengan signifikasi 0,000, sedangkan $\mathrm{F}_{\text {-tabel }}$ pada tingkat kepercayaan (confidence interval) 95\% atau $\alpha=0,05$ adalah 2,28. Dengan membandingkan nilai F-hitung dengan F-tabel, maka F-hitung $(10,339)$ lebih besar dari Ftabel $(2,28)$. Artinya secara serempak variabel experiential marketing yang terdiri dari : sense, feel, think, act dan relate berpengaruh positif dan signifikan terhadap loyalitas pengguna smartphone samsung.

\section{Pengujian koefesien determinasi $\left(\mathbf{R}^{2}\right)$}

Hasil pengujian koefisien determinasi dengan menggunakan program analisis statistik SPSS dapat dilihat pada dibawah ini:

\begin{tabular}{|c|c|c|c|c|}
\hline \multicolumn{5}{|c|}{$\begin{array}{c}\text { Hasil Uji Determinasi } \\
\text { Model Summary }\end{array}$} \\
\hline Model & $\mathrm{R}$ & R Square & Adjusted R Square & $\begin{array}{l}\text { Std. Error of the } \\
\text { Estimate }\end{array}$ \\
\hline 1 &, $480^{\mathrm{a}}$ & ,230 & ,204 & 1,56205 \\
\hline
\end{tabular}

a. Predictors: (Constant), Relate, Think, Sense, Act, Feel

b. Dependent Variable: Loyalitas Pelanggan

Sumber : Data Diolah 2020

Dari tabel terlihat bahwa nilai $R$ Square yang diperoleh adalah sebesar 0,480 atau $48 \%$. Ini menunjukkan bahwa variabel terikat (loyalitas) dapat dijelaskan oleh variabel bebas (sense, feel, think, act dan relate) sebesar $48 \%$, sedangkan sisanya sebesar 0,520 atau $52 \%$ dijelaskan oleh variable bebas lainnya yang tidak diteliti dalam penelitian ini.

$R$ square yang berjumlah 0.230 ini menyimpulkan kolerasi atau hubungan antara loyalitas dengan variabel dari experiential marketing lemah (dibawah standar 0.05) karena hanya dapat menjelaskan sebesar $48 \%$. 


\section{KESIMPULAN}

\section{Kesimpulan}

Berdasarkan hasil penelitian maka dapat ditarik kesimpulan sebagai berikut:

1. Hasil pengujian hipotesis secara serempak (simultan) menunjukkan bahwa variabel experiential marketing yang terdiri dari : sense, feel, think, act dan relate berpengaruh positif dan signifikan terhadap loyalitas pengguna smartphone samsung, Hal ini berarti bahwa experiential marketing yang terdiri dari : sense, feel, think, act dan relate dapat memberikan kontribusi positif terhadap loyalitas pengguna smartphone samsung.

2. Hasil pengujian hipotesis secara parsial menunjukkan bahwa variabel experiential marketing yang terdiri dari : sense, think, act dan relate memberikan pengaruh yang positif dan signifikan terhadap terhadap loyalitas pengguna smartphone samsung sedangkan feel tidak berpengaruh signifikan terhadap loyalitas pengguna smartphone samsung.

3. Hasil pengujian hipotesis secara parsial menunjukkan bahwa think memberikan pengaruh yang dominan. Setiap bertambahnya pengetahuan pelanggan terhadap smartphone samsung (canggih, simple, kualitas baik) maka akan meningkatkan pembelian sebesar $20,9 \%$.

\section{Saran}

Dari kesimpulan yang telah diuraikan diatas, maka peneliti memberikan beberapa saran sebagai berikut:

1. Bagi Akademisi selanjutnya disarankan agar dapat menambah variabel bebas atau menggunakan variabel lain yang berpengaruh terhadap loyalitas pelanggan seperti: citra produk, kualitas produk, promosi dan sebagainya untuk diteliti pada masa yang akan datang. Serta dapat melakukan penelitian yang sama dengan menambahkan responden lebih banyak, karakterisistik responden yang lebih lengkap dan beragam latar belakangnya.

2. Bagi perusahaan samsung diharapkan untuk lebih meningkatkan produk smartphone samsung dalam kecanggihan produk (sensorik smartphone yang cepat, kualitas smartphone yang bagus) serta memberikan pengalaman - pengalaman positif terhadap pengguna smartphone dengan menciptakan inovasi-inovasi terbaru. 


\section{DAFTAR PUSTAKA}

Alma, B. (2015). Manajemen pemasaran dan pemasaran jasa edisi Revisi. Cetakan Kelima. CV. Alfabeta. Bandung

Arikunto, S. (2006). Prosedur penelitian suatu pendekatan. Jakarta: Rineka Cipta.

Ghozali, I. (2006). Aplikasi analisis multivariate dengan program SPSS. Badan Penerbit Universitas Diponegoro

Ghozali, I. (2011). Aplikasi Analisis Multivariate dengan Program IBM SPSS 19, Badan Penerbit Universitas Diponegoro, Semarang. Diponegoro Journal Of Accounting

Griffin, Jill. (2005) Customer Loyalty, Menumbuhkan dan Mempertahankan.

Kertajaya, H. (2007). Marketing In Venus. Gramedia Pustaka Utama.

Kotler , Philips , dan Kevin Lane Keller, (2006). Marketing Management. United State of America. Prentice Hall Internasional.

Kotler, P. (2009). Manajemen Pemasaran Edisi keenam, Penerbit PT. Prenhallindo, Jakarta.

Kotler, P., \& Armstrong, G. (2016). Dasar-dasar Pemasaran, Edisi ke sembilan, Jakarta. PT. Indeks.

Kotler, P., \& Armstrong, G. (2016). Dasar-dasar Pemasaran, Edisi ke sembilan, Jakarta. PT. Indeks.

Kotler, P., \& Keller, K. L. (2012) Marketing Management (14th ed.). New Jersey:Pearson Prestice Hall.

Schmit, B. H. (2005). Experimental Marketing: How to get Customers to Sense, Feel, Think, Act and Relate to Your Company and Brands. European Management Journal, 18(6), 695.

Scmitt. Bernd. (1999) Experiential Marketing. Free Press. New York

Singarimbun, M., \& Effendi, S. (2008). Metode penelitian survai.

Sugiyono (2011) . Metode Penelitian Untuk Bisnis, Penerbit Alfabeta, Bandung.

Sugiyono (2016) . Memahami Penelitian Kualitatif. Bandung: Alfabeta. 